\title{
Espacios y subjetividades: Narrando las trayectorias de la vulnerabilidad*
}

\author{
Spaces and Subjectivities: Telling Trajectories of Vulnerability
}

Espaços e subjetividades: Narrando as trajetórias da vulnerabilidade

\author{
Silvia Grinberg, ${ }^{a}$ Marta Infante, ${ }^{b}$ Claudia Matus, ${ }^{c}$ Ruby Vizcarra. ${ }^{d}$ \\ ${ }^{a}$ Universidad Nacional de San Martin, Argentina. Correo electrónico: grinberg.silvia@gmail.com \\ b Pontificia Universidad Católica de Chile. Correo electrónico: minfantj@uc.cl \\ c Pontificia Universidad Católica de Chile. Correo electrónico: cmatusc@uc.cl \\ d Pontificia Universidad Católica de Chile. Correo electrónico: rvizcarr@uc.cl
}

\begin{abstract}
RESUMEN
En este artículo nuestro objetivo es explorar cómo se producen, reproducen y recirculan espacios y cuerpos que son nombrados como "vulnerables." Nuestra preocupación se instala desde los cambios en el nombrar la pobreza y cómo el concepto de "vulnerabilidad" viene a instalar una nueva forma de regulación de los sujetos a través de condiciones sociales y culturales específicas. El trabajo de análisis se desarrolla en base a dos investigaciones que se realizaron simultáneamente en Buenos Aires, Argentina y Santiago, Chile. En ambos casos, se comparte la preocupación por entender cómo la vulnerabilidad es producida y cómo los cuerpos corresponden a estas ideas. Metodológicamente, utilizamos las narrativas visuales (fotografía y videos) y orales de estudiantes de establecimientos educacionales que viven en contextos de pobreza/vulnerabilidad.
\end{abstract}

Palabras clave: vulnerabilidad/pobreza, espacio, protección, subjetividades, imágenes.

\begin{abstract}
The purpose of this article is to explore how spaces and bodies labeled as "vulnerable" are produced, reproduced, and recirculated in society. Contemporary changes in understanding poverty and vulnerability set up new forms to regulate subjects through specific ways to reason cultural and social conditions. This article includes data from two research projects developed both in Chile and Argentina. In both cases, we explore how social and cultural vulnerability is produced and how bodies are produced as corresponding to these ideas. We analyze students' visual (photos and videos) and oral narratives in contexts of poverty/vulnerability in both countries.
\end{abstract}

Key words: vulnerability/poverty, space, protection, subjectivities, images.

\section{RESUMO}

Objetivou-se explorar como se produzem, reproduzem e recirculam espaços e corpos que são denominados como "vulneráveis". A preocupação começa desde a mudança em nomear a pobreza e como o conceito de "vulnerabilidade" vem estabelecer uma nova maneira de regulação dos indivíduos por meio de condições sociais e culturais especificas. O trabalho de análises desenvolveu-se baseado em duas investigações realizadas simultaneamente em Buenos Aires, Argentina e Santiago, no Chile. Nos dois casos, existe a preocupação em entender como a vulnerabilidade é produzida

* La elaboración de este manuscrito ha sido financiada por FONDECYT, CONICYT (Comisión Nacional de Investigación Científica y Tecnológica), proyecto $\mathrm{N}^{\circ} 1100399$, y PIP-CONICET 11220090100079 , en Chile y Argentina, respectivamente. Las ideas expresadas en este artículo son de exclusiva responsabilidad de las autoras y no reflejan, necesariamente, aquellas ideas de la Comisión. 
e como os indivíduos correspondem a estas ideias. Metodologicamente, utilizam-se narrativas visuais (fotos e vídeos) e orais dos alunos dos estabelecimentos educacionais, que vivem em contextos de pobreza/vulnerabilidade.

Palavras chave: vulnerabilidade/pobreza, espaço, proteção, subjetividades, imagem.

\section{INTRODUCCIÓN}

Luego de años de reformas y políticas neoliberales, ambas, pobreza y vulnerabilidad, se han vuelto parte integral de las descripciones, estudios y prácticas de gobierno (Dean, 1999; Foucault, 2009; Rose, 1999). Es así como las políticas públicas han producido discursos que enfatizan conceptos tales como justicia social, equidad y protección de la población, con el fin de alinear estas políticas con la creación de sociedades democráticas. En los últimos años las políticas educativas han relevado discursos de pobreza y vulnerabilidad estableciendo nuevas lógicas de manejo y regulación de sujetos al interior de las escuelas.

En este marco, pobreza y vulnerabilidad no están referidas sólo a una posición socioeconómica, sino que se ha ido construyendo un entramado discursivo asociado a ellas, en donde se han sumado dimensiones culturales y sociales para "producir" la vulnerabilidad en relación a la pobreza. Por ejemplo, algunas de las variables usadas para la construcción de la vulnerabilidad se encuentran en las estructuras familiares, dimensiones corporales asociadas a "buenos hábitos", la descripción de los espacios en donde viven los y las estudiantes, el uso del tiempo de ocio, etc. De hecho, la noción de vulnerabilidad se ha utilizado para referir condiciones de desigualdad social producidas por el crecimiento del desempleo que generó, entre otros aspectos, nuevos matices en la comprensión de la pobreza, de modo de poder identificar y/o medir niveles de vulnerabilidad.

En este artículo nuestro objetivo es explorar cómo a través de narrativas visuales y textuales jóvenes estudiantes que habitan barrios que se identifican como vulnerables, producen, reproducen y circulan imágenes del espacio que habitan y los efectos que estas ideas tienen en la producción de subjetividades. Dicho de otro modo, nuestra reflexión apunta a entender de qué manera son producidas y reproducidas las ideas de vulnerabilidad por parte de los y las estudiantes que suelen ser definidos como tales. Si existe algo que se pueda denominar vulnerabilidad, creemos que es a través de la noción de espacio que podemos entender de mejor manera las posibilidades e imposibilidades de esta forma de pensar a los sujetos escolares. En este sentido, hablar de espacio implica visibilizar objetos, relaciones, posicionamientos que producen y hacen circular los y las jóvenes que viven en aquellos espacios urbanos usualmente estigmatizados. Así, el eje de interrogación del presente artículo se vuelve hacia los modos y relatos que los y las jóvenes producen sobre sus condiciones de vida, donde el barrio adquiere siempre notas particulares.

El trabajo de análisis se realiza sobre la base de investigaciones que se llevaron a cabo de manera simultánea en la Región Metropolitana de la ciudad de Buenos Aires, Argentina, y en Santiago, Chile. En ambos casos se comparte no sólo la preocupación temática (pobreza/vulnerabilidad), sino también el enfoque teórico (perspectivas postestructurales) y la aproximación metodológica (uso de análisis de discurso en narrativas visuales). En tal sentido, este artículo constituye un esfuerzo por tratar de avanzar en la comprensión de la producción de subjetividades en dos países latinoamericanos.

La forma en que imaginamos y construimos los discursos de "espacio" se convierten en marcos reguladores y normativos para pensar y actuar la pobreza y la vulnerabilidad. 
Como Massey afirma 'El 'espacio' es una de las cosas más obvias que se moviliza como término en una infinidad de contextos distintos, pero cuyos significados potenciales son raramente tematizados o explicitados" (2005a: 103). Efectivamente, cuando las políticas se refieren al 'espacio' lo hacen de un modo naturalizado sin cuestionar su contenido político, se trata de una construcción discursiva que tiende a asociarse a "lugar", extensión o espacio físico que incluye fronteras físicas asociadas a territorios. Siguiendo a Foucault (2009), la soberanía se ejerce en los límites de un territorio, sin embargo, el cómo se ejerce la soberanía en un territorio no tiene por qué ser igual a cómo se ejerce en otro. Cada sociedad o región pone en circulación un conjunto de mecanismos y procedimientos que tienen por función asegurar el poder del soberano y desde allí comprende, construye y administra sus espacios, "la relación de la soberanía con el territorio es lo primordial y sirve de esquema, de grilla para llegar a comprender cómo debe ser una ciudad capital y cómo puede y debe funcionar" (Foucault, 2009: 32). Es a través de esta grilla que la sociedad establece una relación entre soberanía y territorio con fronteras delimitadas, donde es posible la producción y circulación de nuevas funciones en distintos ámbitos como el económico, administrativo y moral. El poder opera en y a través del espacio. El ordenamiento espacial constituye la base para el desarrollo del poder, y "el territorio bien controlado en el plano de su obediencia al soberano es un territorio con una buena disposición espacial" (Foucault, 2009: 32).

Entendido así, el espacio visibiliza una serie de suposiciones tales como que el espacio se ocupa, o que los cuerpos pertenencen a un espacio físico determinado, ambas refieren a la existencia de un límite, borde, que demarca un adentro y un afuera (McDowell, 1999; Massey, 2005a, 2005b, 1994; Matus \& Talburt, 2009). En este sentido, el espacio se construiría como un imaginario que localiza e inscribe al sujeto haciéndolo legible como pobre/marginal/vulnerable.

Esta forma de producir el "espacio" ha permitido la construcción de la distinción entre espacio público y espacio privado, en un tiempo determinado. Al respecto, Bennet, Grossberg \& Meaghan plantean que "la lucha por la posesión del espacio público surgió con la privatización de las tierras agrícolas promulgada por la nueva burguesía en la Edad moderna en Inglaterra y Europa" (2005: 333) ${ }^{1}$. Emerge de este modo un derecho moral asociado a la posesión de los espacios, a la propiedad.

Sin embargo, los procesos de globalización han transformado las ideas de transitar, moverse y habitar espacios, lo que produce cambios en los significados de la vida social, en términos no sólo de espacios ocupados, sino en cómo cada sociedad produce, circula y administra sus espacios en fronteras que ya no son necesariamente físicas, en límites no delimitados claramente. En este sentido, según Bennet, Grossberg \& Meaghan (2005) sociedad y espacio están integrados en un proceso de producción mutua. El espacio ya no es un vacío donde se sitúan objetos e individuos, sino un conjunto de relaciones que delinean lugares (Foucault, 1984). El cómo vivimos, las relaciones que establecemos, los objetos presentes, su posición, no son independientes del espacio, forman parte de él, se producen y re-producen mutuamente (Massey, 2005a, 2005b).

En este artículo nuestro propósito es problematizar, desde las narrativas visuales y textuales de jóvenes estudiantes, cómo la pobreza y la vulnerabilidad se constituyen en sistemas de razonamiento y producción de subjetividades con el fin de comprender cómo se

Traducción libre. 
produce el discurso que permite establecer correspondencia entre espacios/subjetividades/ protección y cuáles son sus efectos en procesos de subjetivación.

Para cumplir nuestro objetivo, primero describiremos la metodología empleada atendiendo a la especificidad de las dos investigaciones, a las características de los estudios y orientaciones del análisis y la comparación. Luego, presentaremos los distintos modos en que operan los entramados discursivos relativos a la protección y el riesgo en los procesos de construcción de subjetividades, a través de las narrativas visuales y textuales de los y las jóvenes participantes. Después, exploraremos cómo las narrativas visuales y textuales de los y las participantes producen, reproducen y circulan imágenes del espacio que habitan, y los efectos que estas imaginaciones tienen en la producción de subjetividades.

\section{DILEMAS METODOLÓGICOS: LAS NARRATIVAS VISUALES COMO FORMAS DE CREAR DISCURSOS}

Problematizar la construcción de subjetividades en el entendido que éstas se producen a través de procesos fluidos, híbridos y complejos, requiere de una aproximación metodológica que dista de una forma tradicional de entender las identidades como estables y con atributos esenciales (Rassmussen, 2006). Por ejemplo, Semetsky indica que "La producción de subjetividades no está basada en ningún código prescrito, sino que es creativa y artística, y también incluye dimensiones éticas y estéticas puntuadas por momentos cuando el yo antiguo simplemente no tiene más sentido" (2006: 3). El aproximarse en las posibilidades del yo significa nuevas formas que escapan de las representaciones convencionales. La idea de utilizar metodologías relacionadas con perspectivas teóricas particulares debe ser problematizada. En este sentido, el potencial de usar imágenes visuales en investigación se está convirtiendo en una ruta usual para aproximarse a procesos reflexivos y complejos de subjetivación en los estudios culturales.

El significado de la fotografía y del video y sus respectivos usos en investigación se transforman para permitir conectarse con los movimientos que hacen emerger al sujeto en co-existencia con el resto del mundo en una suerte de ensamblaje. Siguiendo esta idea, Grosz se refiere a los ensamblajes como "[...] una forma totalmente diferente de comprender el cuerpo en sus conexiones con otros cuerpos, humanos como no humanos, animados e inanimados, relacionando órganos y procesos biológicos a objetos materiales y prácticas sociales" (1994: 165). Desde esta perspectiva, y siguiendo el interés de Deleuze y Guattari (1994), la intención no es centrarse en conceptos específicos y sus supuestas esencias contenidas, sino en el concepto como vehículo de expresión de un evento o de un devenir. Así, un evento sería una singularidad expresada por medio del trazado de un concepto en un plano donde se permiten infinitas e impredecibles relaciones (Semetsky, 2008). El centrarse en los eventos implicaría no sólo habitarlos y comprender sus complejidades, sino considerar "[...] qué fragmentos del pasado o del futuro, son activos en el presente" (Patton, 2006: 36).

El comprender cómo los sujetos emergen en relación con su contexto social implica conectarse con un ensamblaje de eventos desprendidos de lenguajes, textos, prácticas, silencios, entre otros. Esto implicaría "[...] encontrar distintos espesores, lógicas y contradicciones que expresan relaciones de fuerza; relaciones de poder y líneas de fuga" (Grinberg, 2009: 85). 


\section{DISEÑO}

Este artículo desarrolla una mirada reflexiva de las formas en que los sujetos narran visual (videos y fotografías) y oralmente sus experiencias relacionadas con el espacio que habitan. Sus experiencias cotidianas, sus multiplicidades y contradicciones pasan y son mediatizadas en y a través del entramado discursivo. Siguiendo a Massey (2005a, 2005b), todos los elementos del espacio que están relacionados con la elaboración de estas narrativas afectan la construcción de la imagen y del espacio entendido como un evento que está en constante movimiento. De este modo, nos interesa comprender cómo los sujetos se pueden entender a sí mismos a través de la movilización de ideas, signos y códigos de espacio como correspondencia en una trama impregnada de discursos de protección. Mediante el uso de narrativas visuales (videos y fotografías) y narrativas orales, entendidas como efectos de lo que los discursos intentan producir y regular, nuestra intención es problematizar cómo la pobreza y la vulnerabilidad se constituyen en sistemas de razonamiento y producción de subjetividades.

Considerando lo anterior, la investigación propone en su metodología el uso de narrativas visuales y orales que transitan en dos contextos. El primero, se refiere a escuelas públicas chilenas de educación básica en Santiago, con altos índices de vulnerabilidad, y el segundo, a escuelas en extrema pobreza urbana ubicadas en la provincia de Buenos Aires. Mientras en las primeras los y las estudiantes producen registros fotográficos, en las segundas, elaboran videos como formas de narrar las multiplicidades y contradicciones que tiene el habitar esos espacios nombrados como marginales (pobreza y vulnerabilidad), y cómo en esa cotidianeidad se despliegan prácticas discursivas que reflejan la correspondencia entre espacios y subjetividades y que permiten el tránsito y (re)creación de discursos de protección y enfermedad.

El uso de narrativas visuales hace necesario que explicitemos las formas en que abordamos la comprensión de la fotografía y el video en esta aproximación a territorios de "pobreza" y "vulnerabilidad". Como argumenta Sutton (2009), la fotografía usualmente aparece desarticulada de nociones de tiempo y espacio. Al ser vista como un modelo objetivo del mundo, ordena y categoriza tiempo y espacio desde la perspectiva de una imagen. Por otro lado, a pesar de que el cine agregaría la dimensión del tiempo, este obtiene algo de la fotografía que no le es posible alcanzar sólo a través del movimiento. Al imitar la imagen quieta, “[...] esta imagen intenta encontrar una vez más la habilidad para vislumbrar lo desplegado, sensaciones incómodas de tránsito que la fotografía puede lograr" (Sutton, 2009: 50). La inclusión de la fotografía en el cine como principio implica que ésta precisa ser conectada para producir un sentido de movimiento y espacio. Así, cada fotografía no se mueve en sí misma, sino en una cadena de fotografías que implican movimientos abstractos.

De esta forma, el tiempo de la imagen, tanto en la fotografía como en el video, se develan abriendo el instante y permitiendo una constante interpretación. En particular, al referirse a las críticas más tradicionales a favor del cine (video) por sobre la fotografía, Sutton destaca que cualquier dificultad experienciada a partir de las fotografías " [...] no proviene de los modelos o de eso representado, sino de nuestra inhabilidad para articular completamente la extraña sensación del tiempo a medida que se aclara" (2009: 61).

A partir de lo anteriormente expresado, el uso de ambos registros visuales (fotografías y videos) facilitaría un proceso reflexivo sobre las imágenes entendidas como eventos que están ocurriendo constantemente y que requieren de desarrollo y esclarecimiento. Junto con estas imágenes, las narraciones orales de los estudiantes permiten facilitar la comprensión del espacio nombrado como marginal. Nos interesa comprender no sólo cómo se produce 
una práctica discursiva que permite una relación de correspondencia entre espacios y subjetividades, sino cómo operan los flujos, operaciones y efectos de este entramado discursivo en procesos de subjetivación.

El contexto chileno abordado considera tres escuelas básicas públicas (municipalizadas) de la capital que son definidas como vulnerables a través de una medición estatal de la vulnerabilidad (IVE). Participan de esta medición el Ministerio de Educación, la Junta Nacional de Auxilio Escolar y Becas y el Ministerio de Planificación. Desde estas agencias estatales se comprende la vulnerabilidad como un conjunto de riesgos biológicos, psicológicos, socioeconómicos y culturales que tendrían un efecto en la calidad de vida y aprendizaje de los estudiantes (Cornejo et al., 2005). De esta forma, se construye un índice (IVE) a partir de un conjunto de situaciones estimadas como riesgosas entre las que se cuentan una baja escolaridad de los padres, bajo peso corporal de acuerdo a la edad y necesidades médicas, organización y distribución de los espacios familiares, entre otros. En estas escuelas se trabajó con estudiantes, hombres y mujeres que cursan 8 vo año básico entre los años 2010 y 2011. Así, el grupo final estuvo conformado por 15 estudiantes quienes narran sus experiencias cotidianas en el barrio, escuela y alrededores a través de registros fotográficos que ellos mismos elaboran, conversaciones sobre esos registros y entrevistas en profundidad como unidades de análisis.

Por otro lado, el contexto argentino transcurre en escuelas emplazadas en contextos de extrema pobreza urbana del área metropolitana de la ciudad de Buenos Aires del conurbano bonaerense. Como plantea Grinberg, "La villa miseria es la expresión territorial del crecimiento de la marginalidad y extrema pobreza urbana en los últimos años" (2009: 87). La vida cotidiana de los sujetos circula en espacios de gran densidad poblacional y altos índices de contaminación ambiental. Se trabajó, específicamente, en la escuela secundaria común de José León Suárez en donde se encuentran radicadas muchas de las comúnmente llamadas villas miseria que crecieron al compás de la sucesión de crisis de fines del siglo $\mathrm{XX}^{2}$. En esa escuela se desarrolló un taller de video documental junto con docentes y 14 estudiantes. Los estudiantes secundarios participantes del estudio narran sus experiencias en el barrio, la escuela y alrededores a través de estos registros visuales elaborados por ellos mismos. Los contextos descritos son construidos como vulnerables y marginales y con esto producen lógicas particulares de funcionamiento; es así como la trama discursiva constituida por ideas de riesgo y protección produce y circula subjetividades como efecto de estas relaciones de poder.

Nuestra intención es atender a aquellas situaciones experienciales del yo transitando por un evento de multiplicidades, variaciones y contradicciones, donde las narraciones (registros fotográficos, conversaciones sobre éstos, entrevistas en profundidad y videos, respectivamente) permiten hacer visibles procesos de construcción de la otredad.

\section{NARRATIVAS DE PROTECCIÓN. LA AMENAZA DEL RIESGO}

Desde la constitución de las ciudades modernas, las imágenes de inseguridad y miedo han configurado gran parte del paisaje urbano. Si bien, como señala Duby (1995), muchos de nuestros miedos no son tan nuevos y el autor los remonta a tiempos medievales,

Para una presentación más detallada de estos procesos ver Grinberg (2011). 
también es cierto que la vida urbana se ha configurado al calor de la búsqueda de orden, administración y regulación de la vida de la población atendiendo a un conjunto nuevo de acontecimientos que marcaron la vida en la ciudad. De hecho, los múltiples planes de ordenamiento urbano que desde el siglo XVIII comienzan a ponerse en marcha se dirigen hacia la búsqueda de la racionalización y ordenamiento del espacio urbano de forma tal de ofrecer, entre otros aspectos, seguridad y contención a la incipiente población que cada vez más pasaba a habitar los conglomerados urbanos. La ciudad moderna nace en medio de ese relato que hasta nuestros días se construye entre las sensaciones de inseguridad, enfermedad y caos. Como contraparte, la protección se configuró, así, en el relato que aunó gran parte de las acciones que configuraron aquello que Foucault (1999) llamó biopolítica. La protección y el cuidado de la vida desde esos años constituye el horizonte de sentido de gran parte de las instituciones configuradas en esos tiempos. La escuela es, de hecho, una de las instituciones clave en esta tarea de protección y preservación de la infancia.

En línea con lo planteado en el punto anterior, desde la publicación de Emilio por Rousseau, el dentro y fuera son las categorías centrales que definen la vida escolar llamando a preservar a los jóvenes de los males y amenazas sociales. De manera que, si bien, desde las últimas décadas del siglo XX, las sensaciones de violencia e inseguridad así como las políticas del miedo (Pincheira, 2010) se han visto revitalizadas, muchos de estos aspectos son constitutivos de nuestra moderna vida urbana. En qué medida un habitante de las incipientes ciudades decimonónicas se sentiría más inseguro que nosotros no lo podemos saber pero, tampoco, podemos afirmar sin más que todo tiempo pasado fue mejor.

En este apartado nos acercamos a este nudo de cuestiones, pero desde el punto de vista de cómo los jóvenes que viven en el siglo XXI en contextos de extrema pobreza urbana, piensan y se piensan en el medio de estas tensiones. Más específicamente, nos centramos en las formas que los discursos de protección atraviesan la vida de estos jóvenes. Al respecto, cabe señalar que no se trata de aspectos que fueron específicamente objetos de la indagación en el marco de las entrevistas, sino que aparecen como tema y preocupación en las referencias que en sus relatos realizan tanto respecto de la búsqueda de protección, como respecto de las sensaciones de vulnerabilidad que atraviesan sus vidas. Resulta central señalar que en particular son estos jóvenes quienes suelen ser objeto de las diatribas acerca de la inseguridad, sospechados de crimen, violencia y/o inseguridad. De forma tal que aquí resulta interesante la pregunta acerca de los discursos de protección en tanto remite a cómo son marcados, así como a sus sensaciones y vivencias en este sentido. Asimismo, cabe señalar que la creación de espacios de protección ocupa un papel central, en especial cuando se trata de la formación de los jóvenes. La metáfora rousseauniana desde la publicación de Emilio, acompaña los relatos sobre la infancia y la juventud, y desde ya la creación de la escuela moderna.

\section{ESOS OTROS SIEMPRE OTROS}

En algún momento del siglo XIX se tuvo la creencia de que las epidemias y miasmas podían y debían ser controladas; para ello la creación del medio ambiente urbano (Foucault, 1999; Valverde, 2011). En el comienzo del siglo XXI esta situación ya es otra; esa creación del ambiente urbano, en el presente, se configura en un escenario donde conviven espacios altamente desarrollados y tecnologizados, con otros en los que los servicios básicos propios 
del ordenamiento urbano, tales como el agua potable o las cloacas, aún no han llegado. Especialmente en América Latina, las grandes ciudades han vivido procesos constantes de crecimiento que se tradujeron en situaciones de metropolización selectiva (Prevot, 2001), que han dejado viviendo a importantes sectores de la población en espacios urbanos que no fueron objeto de los procesos de racionalización propios de la ciudad moderna. Así, en una suerte de territorios que se encuentran fuera sin estarlo desde fines del siglo XX, han crecido los barrios en donde la pobreza se combina con la degradación ambiental. De esta manera, si la configuración del medio ambiente urbano ha sido una de las primeras preocupaciones de la vida moderna, en el presente nos encontramos con barrios enteros en donde esa preocupación se pone en entredicho, mucho más cuando se trata de sujetos y barrios que están dentro del casco urbano.

\section{Imagen 1}

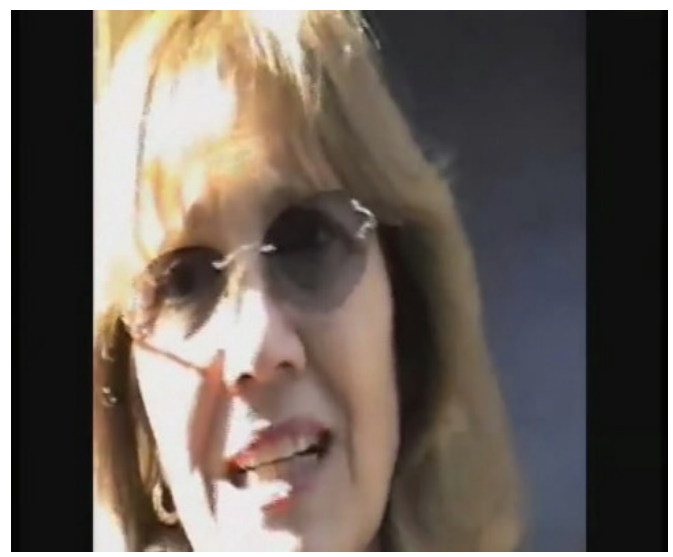

En este marco, "el otro" ya no es alguien que se encuentra fuera de la ciudad. Ya no se trata de quien viene del campo, llega a la ciudad y debe ser objeto de civilización. Nos referimos a quienes nacieron y se han quedado viviendo en villas miseria, favelas o barrios que sin recibir esos motes ${ }^{3}$ se vuelven espacios no-go (Grinberg, Gutierrez y Martiñan, 2012; Osborne \& Rose, 1999). Ahora, si bien es posible para quienes no viven en las villas evitar entrar a estos barrios, se trata de espacios que forman parte de los cascos urbanos, por lo que pueden ser evitados pero no ignorados. "El otro" ya no está fuera sino adentro y queriendo entrar.

En este apartado importa discutir los distintos modos que presentan estos procesos a través de las imágenes y relatos de los jóvenes que refieren tanto a cómo son vistos, pero también cómo miran y eligen mostrar-se. Como señalamos, la cuestión de la protección no radica tanto en la racionalización de esos barrios sino, más bien, en el encuentro que se produce, por TV o simplemente en las calles, con esos "otros" que viven cerca de los rellenos sanitarios. El siguiente es un diálogo entre estudiantes de escuela secundaria y una mujer que vive en una zona céntrica de la ciudad de Buenos Aires, estos jóvenes que viven

"Mote" refiere a una forma de nombrar, una etiqueta que marca en general despectivamente a personas, barrios, instituciones. 
en una de esas villas para cuyas familias la basura es mucho más que desecho:

Yanina: ¿Sabe algo de la quema ${ }^{4}$ ?

E: Sí, lo que sé es que evidentemente eso es un foco infeccioso, que hay una cantidad de deshechos que están en un lugar donde debiera estar limpio [...]

Yanina: Y, usted ¿qué opina? Está bien que vaya o está mal

E: eh $[\ldots]$

Nadir: y $[\ldots]$ dicen que ahí tiran comida

E: iiiNo eso me parece un horror!!!

Nadir: ¿para usted está mal?

E: muy mal

Dalma: ¿y para los que no tienen trabajo?

E: yo soy de capital, vivo en el barrio de Palermo [...] Y en Palermo hay una asociación de gente, de vecinos que empezaron siendo cartoneros [...] y yo considero que lo que hay que hacer es educar a la población para que la basura sea discriminada, tenga un cuidado por parte del estado, por parte del municipio para que pueda ser todo lo que se pueda reciclado de basura en condiciones lógicas y no en las condiciones que lo hace un cartonero que me parece que es terrible porque no tiene protección, ni ningún guante, no tiene protección de ningún tipo y eso hace que pueda enfermarse [...]"(video Re-copada).

Como puede leerse en la Imagen 1 (foto tomada del video realizado por los estudiantes argentinos), estos jóvenes ponen la lente de la cámara sobre la cara de la entrevistada que deja ver en cada uno de sus rasgos ese horror al que refiere. Horror al que estas jóvenes responden acercando más la cámara y transformando esa cara quizá también en horror. Son esos "otros" que la mujer señala deben ser protegidos y educados quienes se paran con su cámara y la interpelan. "Yo soy de capital", señala, "no soy de acá, en capital la cosa es distinta. Hay que educar a la población". Todo un cuerpo de enunciados patologizantes que refieren a esos otros que deben ser objeto de las fuerzas, como señala la mujer entrevistada, protectoras del guante y de la educación.

La escuela de muy diversos modos constituye ese espacio donde "el otro" deviene ese "otro". Como señala un estudiante en Santiago de Chile respecto de un compañero inmigrante:

“Si po’. Cuando hacía desorden le decían “¡Usted es el que hace desorden, peruano!”, le decían. Y un compañero que también era peruano, la profesora de lenguaje, que tiene jasí unos dientes de caballo! Le decían caballo [...] No a la profesora. Y ella le dijo a un compañero peruano bocanegra" (p. 4).

"El otro" en América Latina, desde tiempos coloniales, es objeto de un señalamiento que combina el color de la piel con el desorden y la falta de civilización (Castro Gómez, 2011; Sarmiento, 1849). De hecho, la escuela deviene lugar protegido pero sólo para los buenos estudiantes. Al respecto, uno de los participantes indica:

"Quema" es el nombre que reciben los basurales porque históricamente, dada la acumulación de basura, se procedía a quemarla. 
“[...] me siento protegido porque, ya como mencioné antes, destaco como alumno, suelen protegerme los profesores también. Pero, a otros alumnos no los protegen tanto, y a $[\ldots]$ por su comportamiento, el Inspector suele decirles que los van a expulsar y blablablá, y suelen ser suspendidos [...]" (participante chileno).

Para quienes conforman el grupo de "los otros" aparece el reto, la suspensión, la amenaza de expulsión. Y de hecho es el tipo de vínculo que se construye en el espacio escolar que confirma ese lugar que transforma a quien cruza la frontera, al inmigrante en otro. Ocurre un proceso donde el prejuicio deviene juicio y en esa instancia quien migró vive un proceso de transformación de ese yo en otro que es amenazado de expulsión. Como señala la estudiante en el siguiente relato, "[...] acá yo me transformé, llegó el Inspector, me reta, y me dice siempre que soy igual, que soy igual de 'desordená' que siempre y cuestiones. Llegué a mitad de año acá y yo no quería cambiarme acá, porque allá me sacaba buenas notas y todo eso, pero igual como que acá me transformé, porque yo no era así, tenía buen promedio y todo, pero [...]" (participante chilena).

"Yo no era así" señala esta niña, el desorden y el bajo rendimiento se traducen en una transformación que en el siguiente fragmento, como en el anterior comentario, refiere a una transformación que la dejó marcada en el momento en que devino inmigrante, y en la escuela se lo re-marcaron. Así relata su ingreso a la escuela cuando llego al país, y para referir luego la transformación que vivió al convertirse en la otra, “[...] en principio era perna, tenía buenos promedios, tenía arriba de seis cuando llegué del primer año aquí, pero después bajé el rendimiento, qué duro igual porque de buena pasé a mala [...] quedé como "marcá' en ese sentido" (participante chilena).

Ahora bien, otra cuestión que amerita ser planteada ya no refiere a esa mirada, a esa aceptación sin más del mote de desordenado que acepta sin reparos aquello que le es dado porque, dada su condición, no merece otra cosa. "Qué horror" señala la mujer. Sin embargo, en estos jóvenes muchas veces nos encontramos con otra lectura. "La cosa es que están mal y nosotros queremos que nos cambien de sala", señalan, "las salas, los pisos son de cerámica, la cosa es que están malas y nosotros somos más malos todavía y queremos que nos cambien de sala y seguimos haciendo tira el piso, entonces eso podrían [...] ah, y el techo tiene un hoyo y entra el frío, nosotros pasamos frío en la sala, o tenemos que ir donde está el negocio, comprar un café, un té y tomarnos [algo] para pasar un poco el frío" (estudiante 4).

El desorden muchas veces no es sinónimo de transformación, sino de las pequeñas fisuras que esos otros producen para conseguir que te cambien de sala, para no pasar frío. Este último punto es central ya que refiere a esas pequeñas insurrecciones que expresan ya no tanto el quedar 'marcá', sino pequeñas tácticas que buscan cambiar esas condiciones de des-protección que suele caracterizar a las instituciones en donde esos "otros" circulan. Es esa búsqueda aquella que puede encontrarse en las fotos que toman los estudiantes en Santiago de Chile cuando se les pide que retraten espacios de significación para ellos. En la gran mayoría de los casos las fotos (ver Imágenes 2, 3, 4 y 5) retratan espacios que, justamente, gozan de esa sensación de protección: sus casas, sentados en el sillón abrazados con miembros de sus familias, sus habitaciones siempre impecables o con computadoras que, como señalan al ser consultados, fueron compradas con mucho esfuerzo por sus padres; escenas de trabajo conjunto padre-hija. En todos estos casos, los lugares elegidos presentan imágenes que se escapan de la imagen de riesgo y horror que pesa sobre estos jóvenes y sus barrios. 
Imagen 2

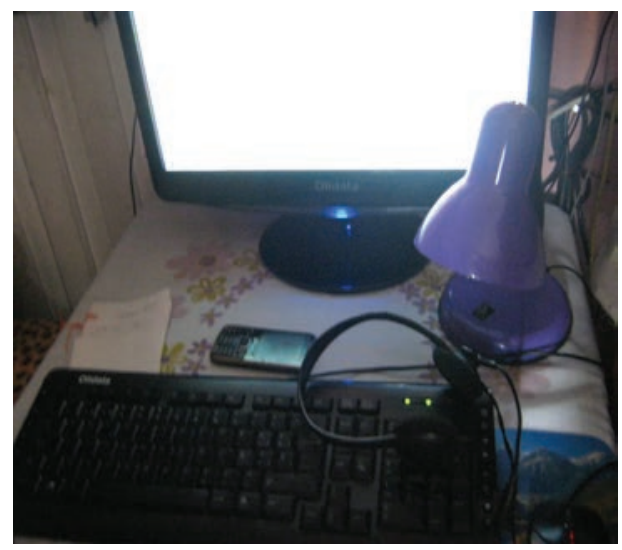

Imagen 4

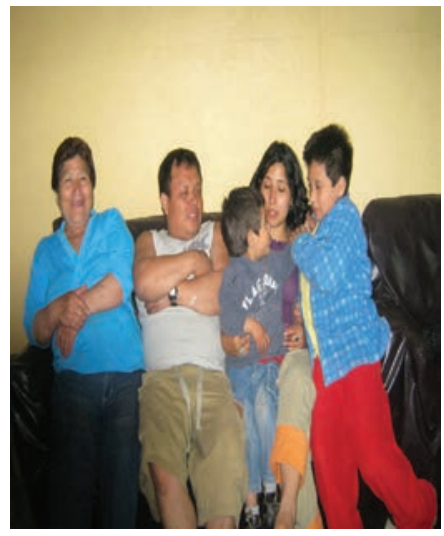

Imagen 3

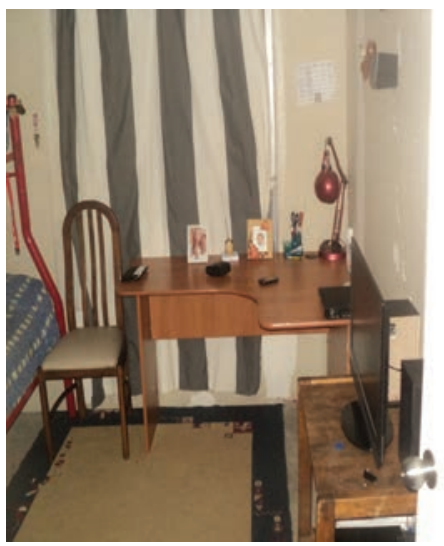

Imagen 5

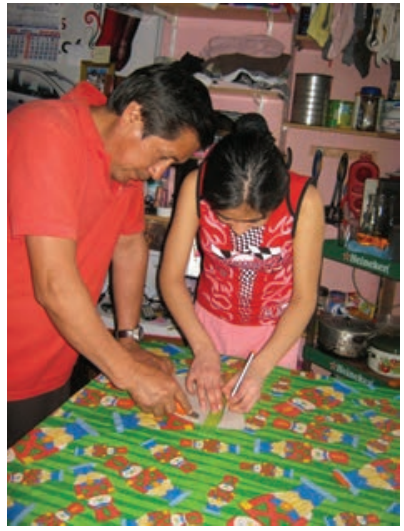

En esta dirección, en el caso de los jóvenes en la ciudad de Buenos Aires, al referir a su barrio reclaman que sean vistos, más que como gente rara, como sujetos "copados" y que alguien se ocupe del barrio en el que viven. De hecho, el video recibe el nombre Re-copada a los efectos de mostrar que el barrio es un lugar copado como la joven que relata y habla sobre su barrio. Así, respecto del video que realizan señalan:

"Está bueno porque estamos mostrando lo que hay en la Cárcova, estamos mostrando algo [...] como algo escondido, que nadie, ningún gobierno, nada se hizo cargo de eso [...] que no existe porque para la gente con plata es como que la Cárcova no existe, como que es un basural donde vivimos nosotros y no es así [...]" (video Re-copada).

Retomando a Valverde (2011), la institucionalización de la zonificación en las ciudades se introdujo, principalmente, para proteger algunos distritos que involucran el emprendimiento privado más que la construcción de la ciudad como espacio protegido. 
Así, como señala ese alumno, se siente protegido en la escuela porque es un buen alumno pero esa protección se vuelve inestable para el resto que aun así sigue buscando esa promesa de bienestar. Hasta aquí hemos referido a las formas en que los sujetos, a través de diversas prácticas, se vuelven el otro que es objeto de etiquetamientos diversos, amenazas de suspensión y expulsión, produciéndose una batería de operaciones por medio de las cuales los sujetos son marcados, y ellos mismos registran y relatan cómo es ese proceso de transformación, de devenir el otro que amenaza. Sin embargo, los jóvenes no se quedan en esos lugares de riesgo y amenaza, aquello que deciden retratar acerca de sus barrios, casas y vida diaria constituye un modo, otro de narrar esas vida, donde lejos de la amenaza aparece el esfuerzo compartido, la ayuda, la amistad, etc.

\section{NARRATIVAS DE CORRESPONDENCIA. ESOS ESPACIOS AL LADO DE LA VEREDA}

En esta sección del artículo nuestro objetivo es explorar cómo las narrativas visuales y textuales de los y las participantes de las investigaciones producen, reproducen y circulan imágenes del espacio que habitan, y los efectos que estas formas de razonar tienen en la producción de subjetividades. De muchas maneras, los espacios narrados por los y las participantes, al ser construidos como "vulnerables," "marginales" y/o "pobres," suponen que son "esencialmente" otros espacios, que están "fuera" de lo reconocible. Nuestro interés de poner atención en cómo los y las participantes construyen ideas específicas de espacio en sus narrativas tiene que ver con los efectos políticos que estas nociones perpetúan. Por ejemplo, si nos remitimos a la forma tradicional de conceptualizar el espacio, en donde éste se entiende como un contenedor de subjetividades, experiencias y objetos (Massey, 2005a, 2005b; McDowell, 1999) lo que se proliferan son órdenes tales como centro/ margen, dominante/resistente, etc. Más importante aún, es que se establecen distancias entre espacios. En el caso de nuestras investigaciones, la construcción de los espacios vulnerables y marginales como simples, rústicos, desolados, poco desarrollados, quedados en el pasado, sucios; y la construcción de los "otros" espacios en oposición, imaginados como urbanos, limpios, modernos, materialistas, alienados, produce esta distancia entre geografías y los cuerpos que los habitan. Estos esquemas totalizantes se entretejen en las narrativas de nuestros participantes.

Cuando los/as entrevistados/as piensan el espacio como una unidad que evoca distancia, lo hacen a través de la permanente referencia de coordenadas, para intencionar los límites de aquello que se puede reconocer como éste $u$ otro espacio y que se resume en frases tales como "los que viven en la Reconquista ${ }^{5}$ son [...]" (participante argentina). La sugerencia de que este lugar tiene su propia epistemología, reproduce aquel lugar que es ajeno al que “otros" habitan. Más complejo aún, políticamente anula la posibilidad de pensar cómo este espacio ha sido producido en relación con ese "otro" espacio. En este sentido, los y las participantes buscan una forma de conectar a las audiencias (aquellos que no pertenecen a este espacio) con el fin de provocar una idea distinta de lo que habitualmente se presenta como el espacio que habitan. Por ejemplo, un estudiante chileno, cuando conversa acerca de un graffiti pintado en una pared de su escuela (ver Imagen 6), argumenta en contra de

Reconquista es el nombre ficticio que se le ha dado a esta zona de la ciudad de Buenos Aires en Argentina. 
esto explicando que esta expresión nubla la imagen que "otros" debieran tener de lo que pasa en su escuela. El participante expresa que "los que miran de afuera esto [grafitti] piensan que adentro en la escuela hay puros callamperos"."

\section{Imagen 6}

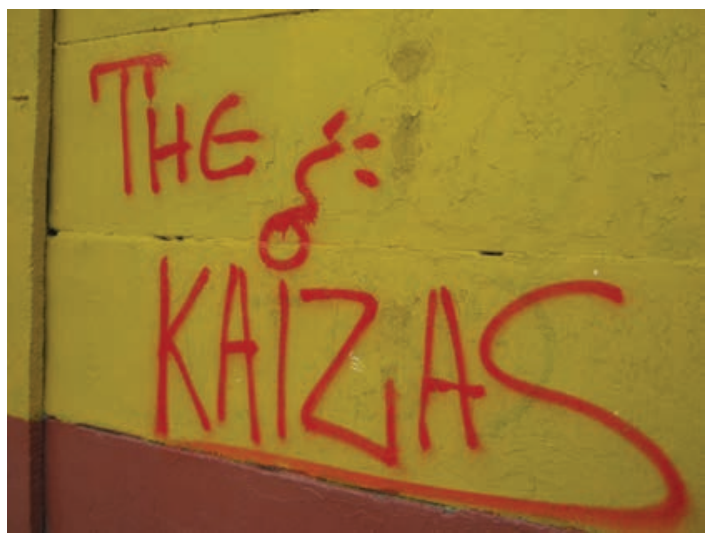

De muchas formas, los y las participantes reproducen ideas de correspondencia entre los espacios y aquellos que los habitan, recirculando nociones de empoderado/desposeído de poder, distancia/cercanía, estereotipo/norma cultural, de tal manera que se transforman en elementos constitutivos de la historia misma. Para que estas imágenes de espacio sean posibles, éste tiene que ser pensado como "dividido, como [constituido] por lugares que ya son separados y contenidos en sí mismos" (Massey, 2005b: 63). Estas formas de concebir el espacio legitima otras ideas como la de progreso, entendida como algo "natural", de ocurrencia supeditada a las "características del espacio" (Matus \& Talburt, 2009). A través de estas ideas es que la constante naturalización de "así es el mundo" es posible. En la medida que los límites y fronteras quedan bien claros y establecidos, se clarifican los "dentro" y "afuera" y se transmite la idea de que los espacios son impermeables, que el cambiar o transformar los espacios vulnerables tiene una motivación que se relaciona con la del progreso.

En otra línea, los registros visuales producidos por los y las participantes insisten en la idea de representar los lugares como formas particulares de organizar y ordenar cuerpos y objetos, que niega el reconocimiento de las multiplicidades, sus intensidades, fracturas y fluidez en su construcción. Por ejemplo, las entrevistadas que elaboran un video mostrando cómo una zona de Buenos Aires es construida como marginal, escogen entrevistar a una mujer que vive "fuera" de Reconquista y ésta utiliza algunos elementos que son claves para ir dilucidando la construcción que existe, desde el "exterior", en relación a lo que define este lugar. La mujer que es entrevistada hace alusión a elementos como la higiene y la desprotección para referirse a lo que ocurre en la Reconquista representándolo como el basural. Al contrario de cómo se narra este espacio desde "fuera", para las estudiantes que narran la Reconquista desde "dentro" plantean que "la gente que no tiene para comer va al basural a

"Callampero" es una forma coloquial de denominar a personas definidas como marginales. 
buscar comida, por lo tanto no se puede cerrar" (participantes argentinas). Más aún, estas participantes plantean que "todos piensan que la Reconquista es un lugar contaminante y que aquí vive gente rara por ser de ahí. Pero no es así. Yo soy de ahí y no soy rara" (estudiante argentina). Desde nuestra perspectiva, estas formas de pensarse son posibles sólo a través de la idea de que el espacio se ocupa, de que los cuerpos ocupan posiciones: la gente rara vive en Reconquista (Buenos Aires, Argentina), la gente vulnerable vive en Independencia (Santiago, Chile).

El imaginar el espacio como bien definido y ajustado a un territorio diferenciado geográficamente de otros se hace en base a la separación, a la permanente construcción del "otro" espacio. En las narrativas de estas participantes está la idea de que las diferencias entre los espacios primero existen, y que luego estos espacios vienen a contactarse. El problema es que estas diferencias, así como se piensan, parecieran ser producto de características internas. Esto, por supuesto, remite a una forma de pensar y construir a los sujetos y lugares como discretos, que refuerza la especificación de límites, de separación de “estos lugares." Es justamente este concepto de espacio el que nos preocupa ya que desde aquí se desprenden unas coherencias, estabilidades y autenticidades que generalmente llevan a elaborar otras nociones totalizantes acerca de las políticas de vulnerabilidad y pobreza asociadas a ciertas características de los espacios.

Por ejemplo, en el caso de la Reconquista, cuando las participantes dicen "pero aquí hay amor y flores" (participante argentina), es una forma de ir presentando estas versiones de las superficies de los espacios con vida, a pesar de las esencializaciones y naturalizaciones. En el caso de una participante chilena, que muestra una fotografía de su pieza, dice:

\footnotetext{
"Me gusta mantener un orden en la pieza, tener ordenadito porque no me gusta mucho [...] si tengo desordenado, después igual tengo que saber ordenar y dejar limpia mi pieza. Porque sin orden $[\ldots]$ porque uno en la vida tiene que ordenar las cosas, tiene que ir ordenando su vida, a mi me gusta tener ordenado, limpio".
}

Ambas formas de narrar ideas más asociadas a "otros" espacios (el sentido estético, la limpieza y prolijidad, son características de "otros" espacios) nos indican cómo las formas de imaginar lugares en oposición, siempre oscurecen estas otras historias que interrumpen las narrativas esencialistas acerca de aquellos/as que los/as habitan.

De muchas maneras las narrativas de las/os entrevistadas/os nos muestran cómo los que son construidos como "vulnerables" y "los que viven en la Reconquista" se convierten en los "vulnerables" y en los que "viven en la Reconquista," a través de estos procesos que no están desvinculados de la producción de diferenciación cultural en la interrelación de los espacios. Para efectos de nuestros análisis, las lógicas que se dibujan a partir de las distintas narrativas, nos muestran que el espacio se constituye a través de las consonancias de las distintas narrativas. Estos lugares narrados por los y las participantes se convierten en estos espacios de coherencia, necesarios para la reproducción del orden "nosotros/ellos".

Nuestro esfuerzo en espacializar estas narrativas tiene que ver con poder entender cómo son producidas las posiciones sociales y culturales ocupadas por los sujetos y cómo son encarnadas. Dicho de otra manera, cómo los sujetos "emergen" de estas formas de pensar el espacio. Las narrativas de los y las participantes nos muestran que ellos/as habitan espacios que existían con anterioridad. Los espacios y sus cuerpos asociados son encriptados por aquellas imaginaciones que circulan como verdades irrefutables. Esta coherencia y 
autonomía en cuanto a pensar los espacios presentados por las/os entrevistadas/os es la que justamente debe ser repensada para poder tener unas aperturas políticas frente a las posibilidades de nombrar y habitar.

\section{CONCLUSIONES}

Las conclusiones de nuestros trabajos tanto en Chile como en Argentina nos han ayudado a problematizar cómo las tramas discursivas generadas en nuestras sociedades en relación a la vulnerabilidad y la pobreza son fuertemente afectadas por otros conceptos como son el riesgo y la protección. En particular, durante los últimos años, dichos conceptos han aparecido con mayor fuerza en políticas educacionales, contextos escolares y discursos gubernamentales. Es así como en nuestro objetivo de problematizar las relaciones entre los sistemas de producción de subjetividades y el espacio, hemos relevado los efectos de las correspondencias fabricadas en función de estas relaciones tradicionales de entender sujeto y espacio.

En este sentido, Guattari y Ronik (2005) enfatizan la necesidad que tienen las sociedades capitalistas de apoyarse en planteamientos irrebatibles de discriminación subjetiva para sostenerse, donde la normativización de los sujetos es un proceso necesario. Estos últimos deben mantenerse en un todo socialmente totalizado de unidades medibles y controlables, orientando la propia experiencia de espacio y tiempo. Así, los estudiantes representan lugares como formas de organizar cuerpos y objetos, negando multiplicidades en su construcción. En otras palabras, siguiendo a Deleuze (2002), el sujeto normativizado se mantiene fuera de la repetición que contempla el devenir en otro continuo. La negación de estas multiplicidades implicaría mantenerse en las dicotomías, en lógicas binarias y en relaciones biunívocas.

Las narrativas de los y las estudiantes nos muestran cómo en sus procesos de subjetivación, enfatizan estados de equilibrio y asimilan su espacio y tiempo a coordenadas que son reconocidas por la sociedad. Es así como al ser visibilizados como sujetos que habitan espacios de marginalidad y vulnerabilidad, reproducen esos conceptos en sus mismos procesos de subjetivación. Se produce una correspondencia entre los espacios y aquellos sujetos que los habitan. Procesos de escisión y marca del espacio urbano, que como supo señalar Foucault (1999), son propios de la constitución de la urbe donde barrios ricos y pobres comienzan a dividirse y diferenciarse como parte de la medicina social que caracteriza a la biopolítica. Así, la escuela, el barrio, aparecen como espacios coherentes y requeridos para la emergencia y reproducción de identidades esencializadas y dicotomizadas, donde el Otro deviene en ese otro nombrado como riesgoso, amenazante y marginal, siempre excediendo a la categoría que lo nombra.

Son estas dinámicas aquellas que hemos encontrado en las narraciones que realizaron los jóvenes donde la sensación de ser el sujeto que amenaza y el par protección/ desprotección se escapan, justamente, a esas lógicas esencializadas. La búsqueda y/o la sensación de protección aparecen en una doble cara. Por un lado, la amenaza o el miedo que generan esos espacios urbanos para quien está fuera y/o pretende estarlo. Definir al otro, ubicarlo en ese lugar de horror, de amenaza y/o negación, oficia como discriminación pero también como resguardo o nota de confirmación de quien se cree fuera pero se sabe no estarlo. Ubicar al otro como otro constituye un modo de ratificar-se fuera de ese lugar 
al que se teme por inseguro pero, más aún, porque se está demasiado cerca. Deleuze y Guattari (1994) refieren al miedo abyecto para referir a esa negación que opera sobre los sujetos y que aquí, proponemos, recae también sobre el espacio urbano (Grinberg, 2011, 2010). Sin embargo, los jóvenes a través de las fotos que toman de sus casas, familias y habitaciones, así como de sus referencias al barrio, operan sobre esa abyección afirmando sus lugares de vida como espacios que les ofrecen seguridad y protección. Es al salir del barrio, en instituciones como la escuela, donde esa protección se quiebra.

Es parte de nuestra convicción que en tanto la identidad y su relación con el territorio sean refutadas, las posibilidades de teorizar lo político del sujeto se abre a nuevas posibilidades. Es así como nos recuerda Erin Manning,

A través de la refutación de la subversión de identidad en el territorio, una experiencia alternativa de tiempo y espacio es imaginada. En este cronótopo efímero alterado, la entrada del otro en el territorio no es más restringida, para ellos no hay un adentro estable que los proteja de un peligroso afuera. Más bien, la alteridad es figurada como pivote alrededor del que las imaginaciones de los cronótopos de acomodación suceden, donde habitar está siempre sujeto a una mutación y redefinición (2003: 25).

Desde las experiencias y narrativas de los/as estudiantes entrevistados/as, la comprensión de las formas tradicionales de teorizar el espacio, como un contenedor a ser ocupado, merece una atención especial, en tanto ésta es la idea que permea las políticas públicas en relación a la vulnerabilidad y la pobreza. El cuerpo vinculado con el espacio que habita produce una orientación nueva para teorizar sobre aquella relación. Cuestionar la esencialización de estas vinculaciones nos adentra en la crítica de las políticas culturales de la escuela y sus efectos sobre las construcciones de los Otros/as.

\section{REFERENCIAS BIBLIOGRÁFICAS}

Bennett, T., Grossberg, L. \& Morris, M. (2005). New Keywords. A Revised Vocabulary of Culture and Society. Oxford: Blackwell Publishers.

Castro Gómez, S. (2005). La hybris del punto cero. Ciencia, raza e ilustración en la Nueva Granada (1750-1816). Bogotá: Universidad Javeriana.

Cornejo, A., Céspedes, P., Escobar, D., Núñez, R., Reyes, G. y Rojas, K. (2005). SINAE. Sistema Nacional de Asignación con Equidad para Becas. Santiago de Chile: Junta Nacional de Auxilio Escolar y Becas. Recuperado de http://www.junaeb.cl/wp-content/uploads/2013/02/libro_junaeb. pdf, consultado en agosto de 2012.

Dean, M. (1999). Governmentality: Power and Rule in Modern Society. London: Sage.

Deleuze, G. (2002). Diferencia y repetición. Buenos Aires: Amorrourtu. \& Guattari, F. (1994). What is Philosophy? New York: Columbia University Press.

Duby, G. (1995). Año 1000, Año 2000: La huella de nuestros miedos. Santiago: Andrés Bello.

Foucault, M. (2009). Seguridad, territorio, población. Buenos Aires: Fondo de Cultura Económica.

(1999). Estrategias de poder. Barcelona: Paidós.

(1984). Des espaces autres. Architecture, Mouvement, Continuité, n. 5, 46-49.

Grinberg, S., Gutierrez, R. y Martiñan, L. (2012). La comunidad fragmentada: Gubernamentalidad y empoderamiento en territorios urbanos hiperdegradados. Revista Espacios Nueva Serie, n. 7, 154-172. (2011). Territories of Schooling and Schooling Territories in Contexts of Extreme Urban 
Poverty in Argentina: Between Management and Abjection. Emotion, Space and Society, vol. 2, n. $3,160-171$.

. (2010). Schooling and Desiring Production in Contexts of Extreme Urban Poverty. Gender \& Education, vol. 22, n. 6, 663-677.

. (2009). Políticas y territorios de escolarización en contextos de extrema pobreza urbana.

Dispositivos pedagógicos entre el gerenciamiento y la abyección. Archivos de Ciencias de la Educación, vol. 10, n. 3, 81-98.

Grosz, E. (1994). Volatile Bodies: Toward a Corporeal Feminism. Indiana: Indiana University Press.

Guattari, F. y Rolnik, S. (2005). Micropolítica. Cartografías del deseo. Buenos Aires: Tinta Limón.

Manning, E. (2003). Ephemeral Territories. Representing Nation, Home, and Identity in Canada. Minneapolis: University of Minnesota Press.

Massey, D. (2005a). La filosofía y la política de la espacialidad: Algunas consideraciones. En L. Arfuch (Comp.), Pensar este tiempo. Espacios, afectos, pertenencias (pp. 101-128). Buenos Aires: Paidós.

. (2005b). For Space. Thousand Oaks, CA: Sage.

. (1994). Space, Place, and Gender. Minneapolis: University of Minnesota Press.

Matus, C. \& Talburt, S. (2009). Spatial Imaginaries: Universities, Internationalization, and Feminist Geographies. Discourse: Studies in the Cultural Politics of Education, vol. 30, n. 4, 515-527.

McDowell, L. (1999). Gender, Identity, and Place. Understanding Feminist Geographies. Minneapolis: University of Minnesota Press.

Osborne, T. \& Rose, N. (1999). Governing Cities: Notes on the Spatialisation of Virtue. Environmental and Planning D: Society and Space, vol. 17, n. 6, 737-760.

Patton, P. (2006). Order, Exteriority and Plat Multiplicities in the Social. In M. Fuglsang \& B. Meier (Eds.), Deleuze and the Social (pp. 21-38). Edinburgh: University Press.

Pincheira, I. (2010). Disciplina, Biopolítica y Noopoder. Acerca de los actuales procesos de constitución de subjetividad. Otros Logos, n. 1, 147-167.

Prevot, M. (2001). Fragmentación espacial y social: Conceptos y realidades. Perfiles Lationamericanos, n. 19, 33-56.

Rasmussen, M. L. (2006). Becoming Subjects: Sexualities and Secondary Schooling. New York: Routledge.

Rose, N. (1999). Powers of Freedom. Reframing Political Thought. Cambridge: Cambridge University Press.

Semetsky, I. (2008). Nomadic Education: Variations on a Theme by Deleuze and Guattari. Rotterdam: Sense Publishers. . (2006). Deleuze, Education and Becoming. Rotterdam: Sense Publishers.

Sutton, D. (2009). Photography, Cinema, Memory: The Crystal Image of Time. Minneapolis: University of Minnesota Press.

Valverde, M. (2011). Seeing Like a City: The Dialectic of Modern and Premodern Ways of Seeing in Urban Governance. Law \& Society Review, vol. 45, n. 2, 277-311. 
